monstrar associação entre o tipo histológico do endométrio e o padrão de sangramento, havendo apenas um caso $(2,4 \%)$ de hiperplasia simples endometrial que persistiu em amenorréia até o nono mês de tratamento, vindo a apresentar sangramento regular na última observação. As demais biópsias realizadas ao final revelaram endométrios atróficos, proliferativos e secretor em respectivamente 17 (41,5\%), 22 (53,7\%) e um $(2,4 \%)$ dos casos. Pode-se, desta forma, concluir que a quase totalidade das pacientes, portadoras de amenorréia e sangramento regular, manteve padrão contínuo e aceitável de sangramento ao longo do estudo e que o regime terapêutico empregado ofereceu boa proteção endometrial, com baixa incidência de estados hiperplásicos.

Palavras-chaves: Progestagênios. Terapêutica de reposição hormonal. Menopausa.

\title{
Desempenho da Mamografia no Diagnóstico do Câncer da Mama em Mulheres de 35 a 50 Anos.
}

Autor: José Tadeu Vicelli

Orientador: Prof. Dr. Luiz Carlos Zeferino

Dissertação de Mestrado apresentada ao curso de Pós-Graduação em Medicina, área de Tocoginecologia, da Faculdade de Ciências Médicas da Universidade Estadual de Campinas, para obtenção do título de Mestre em Medicina, em 30/8/99.

A mamografia, quando devidamente executada, reduz a mortalidade por câncer da mama em mulheres com mais de 50 anos. A validade do procedimento também é indubitável mesmo antes desta idade, não obstante a dificuldade de interpretação, devido à maior densidade do tecido mamário que pode alterar o seu desempenho. Com o objetivo de avaliar o desempenho da mamografia em mulheres entre 35 e 50 anos de idade, atendidas no Ambulatório do Programa de Controle de Câncer da Mama do Centro de Atenção Integral à Saúde da Mulher da Universidade Estadual de Campinas, foi realizado um estudo descritivo, observacional do tipo validação de teste diagnóstico, usando como padrão-ouro o diagnóstico histopatológico ou o seguimento clínico e mamográfico de pelo menos um ano, após o primeiro exame mamográfico e clínico negativo. $\mathrm{O}$ estudo avaliou 1.083 prontuários para o diagnóstico de câncer da mama, de mulheres atendidas no ambulatório de janeiro de 1994 a dezembro de 1997. Foram diagnosticados 191 casos de câncer mamário, correspondendo a $18 \%$ dos casos estudados. Foram calculados valores de sensibilidade, especificidade, valor preditivo positivo, valor preditivo negativo e acurácia da mamografia para a amostra total, cujos valores obtidos foram 82, 96, 81, 96 e 93\%, respectivamente. Estes parâmetros foram avaliados também em correlação com algumas variáveis como: idade, antecedentes familiares para câncer da mama, exame clínico, sintomatologia e tamanho tumoral do estadiamento clínico. Não se observou associação entre o desempenho da mamografia e a idade das mulheres quando analisadas por faixas etárias, assim como em relação ao antecedente familiar para câncer da mama. A sensibilidade foi similar nos dois grupos, sintomáticas e assintomáticas. Por fim, observou-se excelente concordância diagnóstica entre o exame clínico e a mamografia, sendo esta superior quanto maior o tamanho do tumor. Concluiu-se que a mamografia apresentou bom desempenho para o diagnóstico de tumores da mama na maioria dos grupos estudados, é um bom método propedêutico no segundo nível de um programa de controle de câncer da mama em mulheres com 35 a 50 anos, sendo fundamental para diagnosticar tumores com até dois centímetros.

Palavras-chave: Mamografia. Mama: câncer. Câncer: rastreamento.

Autor: Marcus Jose do Amaral Vasconcellos

Orientadores: Prof. Dr. Hermógenes Chaves Netto, Prof. Dr. Soubhi Kahhale

Tese de Doutoramento apresentada à Maternidade - Escola da Universidade Federal do Rio de Janeiro em 26/1/00. Programa de Pós-Graduação em Clínica Obstétrica.

A utilização de um anti-hipertensivo em gestante portadora de hipertensão crônica classificada como não- grave, vem sendo questionada ao longo dos anos. A premissa que a diminuição da pressão arterial mater- 